\title{
Risk Reduction
}

National Cancer Institute

\section{Source}

National Cancer Institute. Risk Reduction. NCI Thesaurus. Code C19694.

Personal behaviors designed to minimize and control the probability and/or impact of unfortunate events. 